\title{
O BLOCO OLÍMPICO: ESTADO, ORGANIZAÇÃO ESPORTIVA E MERCADO NA CONFIGURAÇÃO DA AGENDA RIO 2016
}

FERNANDO MASCARENHAS

Universidade de Brasília / Brasil fernandom@unb.br

Pedro Fernando Avalone Athayde

Universidade de Brasília / Brasil pedroavalone@gmail.com

MARIÂNGELA RIBEIRO DOS SANTOS Universidade do Estado da Bahia / Brasil angelamari.rs@,bol.com.br

NATÁlia NASCIMENTO MIRANDA Universidade de Brasília / Brasil 2nmiranda@gmail.com

\section{Resumo}

A formação da agenda compreende um momento decisivo na formulação de políticas públicas, delimitando um objeto de intervenção governamental. Neste sentido, buscamos avaliar as relações de hegemonia que perpassam a candidatura do Rio de Janeiro à cidade sede dos Jogos Olímpicos e Paraolímpicos. A pesquisa se baseou em levantamento documental construído a partir de fontes institucionais e mídia impressa, discutidos com apoio na técnica de análise de conteúdo. O tratamento e a interpretação dos dados foram organizados à luz da relacional Estado, organização esportiva e mercado, o que permitiu a caracterização do bloco olímpico, ou seja, do bloco de poder inerente aos Jogos Rio 2016.

Palavras-chave: Esporte; Políticas Públicas; Jogos Olímpicos.

\section{EL BLOQUE OLÍMPICO: ESTADO, ORGANIZACIÓN DEPORTIVA Y MERCADO EN LA CONFIGURACIÓN DE LA AGENDA DEL RIO 2016}

\section{Resumen}

La formación de la agenda comprende un momento decisivo en la formulación de las políticas públicas, delimitando un objeto de intervención gubernamental. En este sentido, hemos tratado de evaluar las relaciones de hegemonía que impregnan la candidatura del Río de Janeiro para albergar los Juegos Olímpicos y Paralímpicos. La investigación se basó en una encuesta documental construida a partir de fuentes institucionales y medios de comunicación impresos, discutió sobre la base de la técnica de análisis de contenido. El procesamiento y la interpretación de los datos se organizan en función de la situación relacional, estado, organización deportiva y mercado, lo que permitió la caracterización del bloque olímpico, es decir, el bloque del poder inherente a los Juegos Río 2016.

\footnotetext{
${ }^{1} \mathrm{O}$ presente trabalho foi realizado com apoio do CNPq, Conselho Nacional de Desenvolvimento Científico e Tecnológico - Brasil.
} 
Palabras claves: Deporte, Políticas Públicas; Juegos Olímpicos.

\title{
THE OLYMPIC BLOCK: STATE, SPORT'S ORGANIZATION AND MARKET IN THE SETTING OF RIO 2016 AGENDA
}

\begin{abstract}
The agenda's constitution includes a turning point in public policy formulation, defining an object of government intervention. In this sense, we seek to evaluate the hegemony relationship that pervades the candidature of Rio de Janeiro city to host the Olympic and Paralympic Games. The research was based on documentary survey constructed from institutional sources and press media, discussed based on the technique of content analysis. Treatment and interpretation of data were organized guided by the State's Relational Theory, sport's organization and market, which allowed the characterization of the Olympic block, that is, of the power block inherent to Rio Games 2016.
\end{abstract}

Key-words: Sport; Public Policy; Olympic Games.

\section{Introdução}

As políticas públicas de esporte e lazer no Brasil, desde a realização dos Jogos Pan-Americanos de 2007 e a consequente postulação da cidade do Rio de Janeiro a sede dos Jogos Olímpicos e Paraolímpicos de 2016, oficializada ainda naquele ano, têm sido influenciadas pelo objetivo de projetar o país, tanto no esporte, como na área política e econômica. Em junho de 2008, confirmada pelo Comitê Olímpico Internacional (COI) como candidata, a capital carioca pela primeira vez chegou à fase final do processo de escolha da sede olímpica. Desta vez, malgrado a precoce eliminação na primeira etapa da disputa para os Jogos de 2004 e 2012, o apoio governamental, afiançando os investimentos necessários, e a posição brasileira no cenário internacional parecem ter sido decisivos. Assim, após votação realizada na 121ª Sessão do COI no dia 2 de outubro de 2009, em Copenhague, sob aplausos e muita emoção por parte da delegação brasileira, o projeto Rio 2016 foi anunciado vitorioso. ${ }^{2}$

Como se não bastasse, ao lado dos Jogos de 2016, o Brasil sediará ainda os Jogos Mundiais Militares de 2011, a Copa das Confederações de 2013, a Copa do Mundo FIFA de 2014 e a Copa

\footnotetext{
2 Desde 1999, conforme a Carta Olímpica, o processo de escolha das sedes olímpicas é realizado em duas etapas. $\mathrm{Na}$ primeira, as cidades postulantes respondem a um questionário abordando temas considerados importantes para a organização. Após a avaliação, o Comitê Executivo do COI seleciona as classificadas para a estapa seguinte. Na segunda etapa, as candidaturas oficializadas respondem a outro questionário, mais detalhado. Os documentos são estudados por uma Comissão Avaliadora que, depois de inspeções em cada uma das cidades, produz um relatório que subsidia a decisão final, que ocorre em Sessão do COI a partir de eleição definida pelo método da pluralidade com eliminação, neste caso, definida em três rodadas de votação. Vence, portanto, a candidatura com maioria absoluta dos votos. Anteriormente, o Rio de Janeiro havia perdido na primeira etapa a indicação para os Jogos de 2004, realizados em Atenas, e de 2012, que aconteceram em Londres. Para 2016, foram desclassificadas na primeira etapa as postulantes Doha, Baku e Praga. Além do Rio de Janeiro, eleita a cidade sede, foram classificadas para a segunda etapa Chicago (desclassificada na $1^{a}$ rodada de votação), Tóquio (desclassificada na $2^{a}$ rodada) e Madri (desclassificada na rodada final em disputa direta com o Rio de Janeiro). Informações disponíveis em: http://www.olympic.org/. Acesso em: 2 set. 2010.
} 
América de 2015. Por conseguinte, os megaeventos esportivos passaram a constituir o princípio organizador da agenda de esporte e lazer do país. A III Conferência Nacional do Esporte (CNE), realizada no primeiro semestre de 2010, evidencia tal suposto. Depois de pautar-se pelos temas "Esporte, Lazer e Desenvolvimento Humano" (I CNE, 2004) e "Construindo o Sistema Nacional de Esporte e Lazer" (II CNE, 2006), a III CNE apresentou para discussão o "Plano Decenal de Esporte e Lazer" que, subordinado ao slogan "Por um time chamado Brasil", foi construído a partir de metas e ações em torno de "10 pontos em 10 anos para projetar o Brasil entre os 10 mais" (Brasil, 2010). Estes são, portanto, os termos do debate que atualmente circunscrevem a agenda esportiva brasileira.

Mas como os megaeventos esportivos surgem como pauta no âmbito dos governos, da mídia, do mercado e do próprio mundo esportivo, tornando-se central na organização das políticas de esporte e lazer do país? A formação da agenda compreende um momento decisivo na formulação de políticas públicas, caracterizando-se como um processo em que determinados temas emergem, delimitando um objeto de intervenção governamental. Ocorre que este processo envolve diferentes visões e interesses, mobilizando agentes específicos da sociedade civil e do Estado, que fundamentam suas argumentações no sentido de regulamentar e influenciar ações que conferem materialidade à política (Melo, 2007). Neste sentido, nosso objetivo consiste em avaliar as relações de hegemonia que perpassam a formação da agenda esportiva no atual momento histórico, bem como analisar seus efeitos sobre as ações e metas propostas pelo Plano Decenal de Esporte e Lazer.

Destaca-se, no entanto, que esta investigação, vinculada ao projeto "Megaeventos e Plano Decenal: um estudo sobre a agenda esportiva brasileira", ${ }^{3}$ compreende duas fases de pesquisa, uma dedicada à avaliação de como o tema dos megaeventos emerge na agenda pública e outra à análise do Plano Decenal. Logo, o escopo deste texto restringe-se à difusão dos resultados da primeira fase, o que compreende a discussão em torno dos interesses envolvidos na candidatura e projeto olímpico brasileiro, considerando a configuração da agenda como chave interpretativa dos posicionamentos e ações ante a realização no país dos Jogos Olímpicos e Paraolímpicos de 2016.

\section{Delineamento do estudo}

Este estudo pode ser caracterizado como uma pesquisa de caráter qualitativo que se apoiou em levantamento documental construído a partir de fontes institucionais e material produzido pela mídia impressa. As seguintes fontes institucionais foram pesquisadas: (i) notícias publicadas pela Assessoria de

\footnotetext{
${ }^{3}$ Projeto desenvolvido no âmbito do Grupo de Pesquisa e Formação Sociocrítica em Educação Física, Esporte e Lazer - AVANTE, com apoio do CNPq e com as contribuições de Guilherme Nunes, Leonardo da Silva, Marcos Paulo, Pedro Osmar Figueiredo, Simone Tourinho, Wagner Matias e Zenildo Caetano da Silva, alunos da disciplina "Tópicos Especiais - A inserção dos megaeventos na agenda esportiva brasileira", vinculada ao Programa de Pós-Graduação em Educação Física da UnB, a quem agradecemos.
} 
Comunicação do Ministério do Esporte (ME); ${ }^{4}$ (ii) portal eletrônico do COI; ${ }^{5}$ (iii) portal eletrônico do Comitê Olímpico Brasileiro (COB); ${ }^{6}$ (iv) portal eletrônico dos Jogos Rio 2016; ${ }^{7}$ e, (vi) Dossiê de Candidatura ${ }^{8}$. No que corresponde ao material da mídia impressa, a fonte foi o acervo do jornal Folha de S. Paulo (FSP). ${ }^{9}$ Considerando o objeto da investigação, registramos que o levantamento foi realizado nos marcos de um recorte cronológico correspondente ao período de $1^{\circ}$ de setembro de 2006 a 29 de julho de 2010, isto é, desde a Assembleia Geral do COB que definiu o Rio de Janeiro como cidade postulante a sede olímpica até a data de divulgação do Host City Contract, que é o contrato firmado entre o COI e a cidade sede, avalizado pelo governo federal.

Juntos, comunicação governamental, dados das entidades de administração do esporte olímpico em nível internacional e nacional, do comitê organizador e produção midiática, bem como o próprio projeto institucional dos Jogos, fornecem um expressivo material para o estudo da agenda. Quanto ao tratamento deste material, com a pretensão de se alcançar o significado das informações, enunciados e termos expressos pelos documentos, inferindo os interesses presentes, foi utilizado o método de análise de conteúdo (Bardin, 2010; Franco, 2005). Assim, a atividade de pré-análise, realizada a partir da leitura flutuante de todo material, permitiu a definição de um corpus de análise constituído por 875 registros da FSP e 162 do $\mathrm{ME},{ }^{10}$ além de todo material dos portais e documentos citados, estes últimos, utilizados como recurso suplementar da investigação.

A fase de análise propriamente dita, o que envolveu a exaustiva leitura de todo o conteúdo, foi balizada por um quadro teórico construído por meio de revisão de literatura relativa aos temas Políticas Públicas, Políticas Esportivas e Estudos Olímpicos. Partindo dessa organização, bem como de constantes idas e vindas da teoria aos dados, passamos a discussão e aos resultados da investigação, cujos recortes de análise a serem apresentados foram organizados a partir da categorização que orientou o agrupamento, tratamento e interpretação do material, qual seja, Estado, organização esportiva e mercado.

\section{Estado}

\footnotetext{
${ }^{4}$ Disponível em: http://www.esporte.gov.br/ascom/pesquisaNoticia.do.

${ }^{5}$ Disponível em: http://www.olympic.org/.

${ }^{6}$ Disponível em: http://www.cob.org.br/home/home.asp.

7 Disponível em: http://www.rio2016.org.br/.

8 Ver: Comitê Rio 2016 (2009).
}

9 A opção pela FSP baseou-se em dois critérios: (i) acessibilidade, uma vez que o jornal possui um acervo digitalizado de suas edições anteriores com um sistema de busca de fácil utilização operado por descritores; e, (ii) representatividade, pois é um dos jornais de maior circulação no país. Disponível em: http://www1.folha.uol.com.br/fsp/arquivo.htm.

10 Conforme busca operada pelos descritores "Jogos", "Olimpíadas" e "Rio 2016", foram selecionados inicialmente 1.685 registros a partir do portal da FSP e 200 registros do ME. Após a leitura flutuante, parte destes registros foi desprezada por não se relacionar diretamente ao tema pesquisado. 
Um dia após o anúncio do Rio de Janeiro como cidade sede dos Jogos de 2016, no sábado, 3 de outubro de 2009, 25 registros pautaram o acontecimento na FSP. Os temas abordados, além do processo de eleição da sede olímpica, envolveram as oportunidades e desafios que se abriram com o êxito da candidatura, a comemoração dos brasileiros, a festa organizada em Copacabana e a decepção dos concorrentes. Destes registros, chamaram atenção várias referências ao presidente Lula, chefe de Estado e de governo, um entusiasta da realização dos Jogos. Mike Lee, o marqueteiro da campanha, avalia que Lula foi o personagem central da vitória. ${ }^{11}$ Isto, por seu carisma e capital simbólico acumulado, o que se traduziu em prestígio e trânsito diante das organizações e outras lideranças no plano internacional.

Destaca-se também o investimento pessoal de Lula na candidatura, algo que se justifica tanto por sua paixão pelo esporte, muitas vezes declarada, ${ }^{12}$ como por sua percepção sobre o que representa sediar os Jogos Olímpicos no plano das relações externas e concorrência global, em nossa análise, postura que se vincula a sua perspectiva de transformação e mobilidade, traço constituinte de sua trajetória e conduta política. ${ }^{13}$ Não por acaso, logo após a escolha do Rio, Lula comemorou: "Deixamos de ser um país de segunda classe. Ganhamos a cidadania internacional". ${ }^{14}$ A declaração é expressão de um processo em que o esporte e os Jogos Olímpicos foram inscritos em seu projeto de mobilidade da nação.

Óbvio que o envolvimento governamental, a convergência e a coalizão de interesses em prol da candidatura olímpica brasileira, em grande medida, definiram-se a partir da vontade e empenho do condottiere e do mito, isto é, do chamado lulismo. ${ }^{15}$ Contudo, no sentido de decompor a totalidade relacional e nexos de determinação que dinamizam tal processo, há de se observar o projeto Rio 2016 na sua articulação com o projeto mais geral de soberania e desenvolvimento nacional matizados pelo governo de Lula. Queremos dizer com isso que os estudos e pesquisas sobre o projeto olímpico

\footnotetext{
11 "Lula foi mais importante do que Blair, diz consultor". Folha de S. Paulo, 6 out. 2009.

${ }^{12}$ Uma forte demonstração da paixão de Lula pelo esporte está presente em seu discurso na cerimônia de sanção da Lei da Timemania (Lei n ${ }^{\circ}$ 5.524/06), em 14 set. 2006: "Antes de ser presidente da República, eu sou brasileiro. Antes de ser presidente da República, eu sou fanático por esporte e, dentro do esporte, o futebol. E antes de ser presidente da República, eu sou torcedor" (apud Boudens, 2007: 10).

${ }^{13}$ Segundo Paraná (2008), a conduta política e matrizes discursivas de Lula se forjam num esforço de emancipar os brasileiros da "cultura da pobreza" e, pela "cultura da transformação" - encarnada em Lula e sua família -, substituir a visão imediatista e conformada do mundo por uma ligação com o futuro e com a superação dos problemas atuais, para o surgimento de desejos e ações mais solidários e coletivos, para a mobilidade dos homens e da nação.

14 "Com a Olimpíada, Brasil pode superar vira-latice". Folha de S. Paulo, 4 out. 2009.

15 A força e importância de Lula substituem o debate em torno do programa de governo e dá origem ao fenômeno do lulismo, o que, para Singer (2009), corresponde a um projeto sem rupturas e pluriclassista, marcado ainda por uma forte identificação dos pobres - ou seja, do subproletariado - com a figura de Lula. Para além do combate à desigualdade dentro da ordem, o Lulismo sustenta-se também pelo carisma, história e origem de classe do presidente, o que se soma ainda a sua habilidade discursiva, na qual o sentido metafórico do esporte é recorrentemente utilizado. Sobre este último tema, ver: Sardinha (2008).
} 
brasileiro devem considerar, de um lado, o modelo econômico em curso - ou seja, o neodesenvolvimentismo - e, de outro, a política externa de reposicionamento do país na geopolítica mundial.

No que toca às relações exteriores, as ações do governo orientaram-se por um papel de liderança política e econômica no continente latino-americano, o que se somou ao maior protagonismo nos grandes fóruns internacionais. Além disso, demonstraram uma atuação ativa frente às questões e temas da agenda global - reforma do Conselho de Segurança da Organização das Nações Unidas (ONU), Estados Unidos e Alca, fortalecimento do Mercosul, cooperação Sul-Sul, Fundo Monetário Internacional (FMI) e política de condicionalidades, capitais voláteis, Organização Mundial do Comércio (OMC) e negociações comerciais multilaterais, G-20, aliança dos BRICS etc. De acordo com Almeida (2004), ao se fazer ouvir nas decisões em torno dos grandes problemas da comunidade internacional, a diplomacia do governo Lula proclamou uma maior presença do Brasil no mundo, alçando-o à condição de potência e autêntico global player.

Neste contexto de intensa atividade diplomática, os megaeventos esportivos acabaram por ocupar lugar de relevo. Sua importância fica evidente pela criação, na estrutura do Itamaraty, em 2008, de uma coordenação específica para tratar de cooperação esportiva. ${ }^{16}$ A partir daí, todas as embaixadas e consulados do Brasil receberam orientações para a promoção da candidatura olímpica. Foi ainda estabelecido um plano de ações para que diplomatas brasileiros contatassem membros do COI, presidentes de federações esportivas e de comitês olímpicos nacionais, bem como autoridades governamentais e personalidades do esporte que pudessem influenciar a escolha da cidade sede. Por sua vez, o presidente Lula pautou o projeto Rio 2016 em diversos encontros bilaterais com chefes de Estado e de governo nos anos de 2008 e 2009, ${ }^{17}$ além de comparecer à abertura de Pequim 2008 e visitar o Parque Olímpico de Londres, em 2009, demarcando o interesse do país pela organização dos Jogos (Resende, 2010).

\footnotetext{
16 A Coordenação-Geral de Intercâmbio e Cooperação Esportiva (CGCE), vinculada ao Ministério das Relações Exteriores (MRE), foi criada para tratar do tema esporte na agenda da política externa brasileira. "É responsável por coordenar as ações de cooperação esportiva entre o Brasil e outros países, bem como com instituições internacionais e entidades esportivas; coordenar ações do Governo Federal que promovam intercâmbio de experiência com outros países na organização de megaeventos esportivos; e representar o Itamaraty em comitês interministeriais relacionados à realização de megaeventos esportivos" (Resende, 2010: 38).

${ }^{17}$ Em um destes encontros, durante o Congresso da ONU realizado em Nova York, em setembro de 2009, depois de conversações com o rei espanhol Juan Carlos, junto com o primeiro-ministro Jose Luiz Zapatero, Lula selou um acordo eleitoral entre os governos do Brasil e da Espanha de mútuo apoio para a eleição da sede olímpica. Assim, caso Rio de Janeiro ou Madri saíssem da disputa no primeiro turno, o que não aconteceu, a perdedora apoiaria a remanescente na sequência das votações contra as outras concorrentes, Chicago e Tóquio. "Para os outros, serão apenas outros Jogos, mas, para o Brasil, seria algo para aumentar a autoestima do povo, pois nenhuma cidade precisa dos Jogos, o Brasil precisa", afirmou Lula. "Espanha confirma pacto com Brasil por Jogos-2016". Folha de S. Paulo, 23 set. 2009.
} 
Os megaeventos eventos esportivos e, particularmente, a realização dos Jogos no Rio de Janeiro, são vistos como parte de um projeto que, ao mesmo tempo, garante transformação interna e reformula a imagem externa brasileira. A justificativa compreende argumentos em favor dos Jogos como um catalisador de obras e investimentos, dinamizando a economia e fortalecendo a posição da cidade e do país no mercado mundial. Deste modo, ainda que superestimados, os impactos sociais e econômicos esperados dos Jogos Rio 2016 se articulam ao próprio projeto nacional idealizado pelos intelectuais governistas, (Mercadante, 2010; Pochmann, 2009; Souza, 2003; dentre outros). Trata-se de um projeto ou modelo de desenvolvimento pautado na manutenção da estabilidade e ação distributiva do Estado, este último, um Estado mais forte, induzindo o crescimento e coordenando os investimentos no país a partir de estratégias de planejamento de longo prazo.

Em linhas gerais, o modelo de desenvolvimento que se configura no governo Lula, em especial, a partir de seu segundo mandato, entre 2007 e 2010, denominado neodesenvolvimentista, sintetiza-se a partir de três eixos: o financiamento do crescimento econômico, o que está ligado à política de aliança com o capital nacional, pela qual o governo, por meio do Banco Nacional de Desenvolvimento Econômico e Social (BNDES), empenhou-se em fortalecer as empresas nacionais com atuação em setores estratégicos e competitividade internacional; o investimento em grandes obras de infraestrutura - saneamento básico, habitação, estradas, portos, hidrelétricas etc. -, recuperando um papel mais ativo do Estado através Programa de Aceleração do Crescimento (PAC); e, a recuperação da capacidade do Estado de prover políticas sociais, sobretudo, políticas de inclusão e redução da pobreza, dentre as quais o Bolsa Família é a mais emblemática. ${ }^{18}$

$\mathrm{Na}$ relação mais direta deste modelo com o projeto olímpico, num movimento combinado, enquanto o Estado investidor garante as grandes obras de infraestrutura, o Estado financiador opera na concessão de crédito aos grupos empresariais envolvidos com a construção das arenas esportivas, expansão da rede hoteleira e serviços turísticos, incremento em tecnologias de informação e telecomunicações, dentre outros setores. A título de exemplo, vejamos o que advogam representantes BNDES sobre o papel do Estado frente ao projeto olímpico:

O esforço de investimentos deve envolver um volume significativo de recursos federais, considerando que a capacidade de investimento da cidade do Rio de Janeiro, é relativamente limitada. É preciso que haja uma coordenação de iniciativas a cargo do Governo Federal - assim como ocorreu em 2008 no caso da China, ressalvadas as

18 Segundo Singer (2010: 110), o governo de Lula forma a síntese contraditória das "duas almas" que hoje habitam o PT. "Foi o fato de ter implementado, simultaneamente, políticas que beneficiam o capital e promovem a inclusão dos mais pobres, com uma melhora relativa na situação dos trabalhadores, que permitiu a convivência dos princípios estabelecidos em sua fundação, em 1980, e as diretrizes do programa de governo apresentadas em 2002". Viveu, assim, o contraditório entre a transformação inspirada nos ideais éticos da radicalização da democracia e aprofundamento da justiça social e a adoção de uma política desenvolvimentista que agrega o "social" como acessório. 
diferenças de regime político, que torna mais difícil a centralização decisória numa democracia - e que este opere também como um grande financiador do evento, além de arcar com parte relevante do esforço de investimento. Seja como investidor através de recursos do Orçamento Geral da União (OGU), ou como financiador, através do BNDES a taxas favoráveis, o apoio do Governo Federal ao projeto olímpico se justifica plenamente (Giambiagi et al., 2010: 17-18).

Igualmente sintonizada com o propósito de fazer com que os Jogos se materializem como um catalisador de desenvolvimento, ao comemorar a vitória da candidatura brasileira, a então ministra da Casa Civil, Dilma Roussef, anunciou: "Vamos fazer a melhor Olimpíada de todos os tempos. O governo federal não vai faltar, vamos usar todos os recursos que o Brasil tem”. ${ }^{19} \mathrm{E}$ em alusão ao PAC, implementado em vários setores e regiões do país, Dilma prometeu um verdadeiro "PAC Olímpico" para o Rio de Janeiro, reunindo obras e ações envolvendo a infraestrutura de portos e aeroportos, o transporte, a habitação, a segurança pública, a educação e a saúde, o que inclui a urbanização e pacificação das favelas, projeto visto como um pré-requisito social para a preparação da cidade.

A mesma análise e promessa são reproduzidas pelo ME:

Grandes comunidades pobres do Rio estão sendo beneficiadas com intervenções urbanas do PAC já em andamento. "O investimento do PAC no Brasil e na cidade do Rio de Janeiro vai muito além do objetivo de conquistar os Jogos Olímpicos. É um programa bem articulado, que pensa o País de forma integrada, com olhar no futuro", afirmou o secretário do Ministério do Esporte para a candidatura Rio 2016, Ricardo Leyser. "O PAC atesta o comprometimento do Brasil com políticas públicas de longo prazo e essenciais ao desenvolvimento sustentável. Com isso, naturalmente ajuda a fortalecer a postulação do Rio a sede dos Jogos”, acredita o secretário. Ele explica que "O dossiê de candidatura espelha todos os projetos de desenvolvimento econômicosocial que estão sendo implementados no Rio". ${ }^{20}$

O projeto de urbanização e pacificação das favelas, além da intervenção militar, compreende ainda a providência do Estado social que, ao lado de um conjunto de políticas governamentais de ampliação do mercado de massa, como o próprio Bolsa Família, o controle dos preços da cesta básica, o aumento real do salário mínimo, o microcrédito, dentre outras ações, faz com que uma política intersetorial de segurança também suba os morros cariocas. Estamos nos referindo ao Programa Nacional de Segurança com Cidadania (PRONASCI), ao qual se articulam as políticas sociais do ME organizadas a partir do Programa Segundo Tempo (PST) - associado ao Programa Mais Educação, do Ministério da Educação (MEC) - e do Programa Esporte e Lazer da Cidade (PELC), com ações voltadas à juventude em conflito com a lei ou em situação de vulnerabilidade social.

O governo vai praticamente dobrar o total de verbas de segurança com destino ao Rio de Janeiro por conta da obtenção da Olimpíada-2016. A partir de 2012, o Ministério da

19 "Dilma torce, chora e afirma que irá controlar gastos". Folha de S. Paulo, 3 out. 2009.

20 "Rio 2016: governo federal se organiza para a candidatura brasileira aos Jogos Olímpicos". Portal de notícias do ME, 29 mar. 2009. 
Justiça prevê investir no Estado $\mathrm{R} \$ 700$ milhões só neste setor. Esses repasses serão feitos por meio do PRONASCI, que abrange dinheiro para atender a jovens de comunidades carentes, fornecimento de armamento e outros equipamentos, além de tropas adicionais. ${ }^{21}$

Conforme argumentam representantes do BNDES, tais ações, caso obtenham sucesso na redução dos índices de violência naquela que é tida como uma cidade símbolo do problema da violência no Brasil, por si só, confirmariam o legado positivo do pós-evento, pois a regeneração de espaços e territórios de desvalia, as favelas cariocas, melhoraria a imagem do país e acarretaria o maior ingresso de turistas, além de refletir positivamente na atração de investimentos externos (Giambiagi et al., 2010). A despeito deste e do conjunto de legados anunciados, ${ }^{22}$ o que embala o projeto olímpico, menos que necessidades sociais, são os interesses pró-mercado voltados à dinamização da economia.

Enfim, o que fica claro é uma ação firme do governo Lula no apoio aos Jogos Rio 2016, o que se desdobra pelos compromissos assumidos de financiamento ao empreendedorismo de grupos privados associados aos negócios que envolvem a preparação para o evento, do investimento estatal em obras de infraestrutura e do incremento de programas e ações de manejo social do risco, isto é, em políticas sociais focadas nas condições de segurança da cidade. Vale advertir, no entanto, que mesmo que tais ações indiquem o protagonismo do Estado no processo de organização dos Jogos, o desempenho deste papel e a própria soberania nacional devem ser analisados à luz dos limites e exigências impostas pelo COI.

\section{Organização Esportiva}

É política do COI ter participação ativa na execução do projeto dos Jogos, com seu próprio plano geral de organização. Isto porque a evolução do marketing olímpico transformou o evento esportivo Jogos Olímpicos num megaevento empresarial, um empreendimento efêmero, mas enormemente lucrativo e totalmente inserido na economia política global, algo bem distante da competição limpa de interesses políticos e comerciais, voltada ao engrandecimento da cultura atlética e

\footnotetext{
21 "Jogos turbinam segurança no Rio". Folha de S. Paulo, 5 out. 2009.

22 Os legados previstos são: (i) transformação da cidade - renovação da infraestrutura urbana, melhorias no transporte, segurança e meio ambiente; (ii) inserção social - para a habitação, é citada a construção da vila olímpica, com 24 mil quartos, para o treinamento, é anunciada a participação de 48.000 voluntários nos Jogos, e para o emprego, há a perspectiva de criação de 50 mil vagas temporárias e 15 mil permanentes; (iii) juventude e educação - meta de ampliação do PST, com o atendimento saltando de 1 milhão para 3 milhões de jovens, além do investimento de 400 milhões de dólares no Programa Mais Educação e duplicação do número de participantes nos Jogos Universitários Brasileiros (JUB's), chegando a 5 milhões de atletas universitários; e, (iv) esportes - aumento do Programa Bolsa-Atleta, estendendo-o para 11 mil bolsas, o aumento nos investimentos no esporte olímpico e paraolímpico, calculado em 210 milhões de dólares, a construção de novas instalações esportivas de treinamento, sendo 14 fora do Rio de Janeiro e 29 na cidade, a formação de técnicos oficiais, em especial, para os esportes menos desenvolvidos, e o aumento dos investimentos privados no esporte, estimados em 200 milhões de dólares, por meio de incentivos fiscais (Comitê Rio 2016, 2009).
} 
educação do caráter, como preconizava o ideal olímpico. Desde Los Angeles 1984, a entidade transformou os Jogos num sofisticado projeto de negócios e fonte de receitas. Para se ter uma idéia, os direitos de imagem para Moscou 1980 custaram US\$ 88 milhões, em Pequim 2008, US\$1,7 bilhão. ${ }^{23}$ O fato é que, a partir da gestão de Juan Antonio Samaranch, ${ }^{24}$ “os valores dos contratos assinados pelo COI - que tratou de centralizar a comercialização das Olimpíadas - cresceram em progressão geométrica e converteram os famosos cinco anéis de Coubertin numa marca mundialmente mercantilizada" (Proni, 2004: 6).

Não é de se estranhar, portanto, as disputas e tensionamentos gerados a cada novo ciclo de escolha da sede olímpica. Conforme relatam Simson e Jennings (1992), há muito poder e dinheiro envolvendo os Jogos e a prática da "cartolagem" no Movimento Olímpico. Neste contexto, a candidatura Rio 2016 foi também uma prova de força para Jacques Rogge, pois a vitória carioca abriu caminho para sua reeleição como presidente do COI. ${ }^{25}$

A força política de Rogge no grupo ficou clara com a escolha do Rio para os Jogos de 2016. Simpático à candidatura carioca desde o início, embora não tenha se manifestado publicamente, o belga ganhou a disputa interna com o grupo ligado a seu antecessor, Juan Antonio Samaranch, cujo filho, Juan Antonio Samaranch Jr., pilotava a candidatura de Madri, derrotada pelo Rio na rodada final por 66 votos a 32. ${ }^{26}$

Seguindo uma lógica de continuidade e descontinuidade - ou seja, de modernização conservadora -, oscilando entre a tradição aristocrática e a organização empresarial, mesmo que aberto aos interesses comerciais da mídia e patrocinadores, o Movimento Olímpico e suas instituições, historicamente, organizam-se como um sistema fechado e elitista, garantindo aos seus mandatários a auto-reprodução no poder (Tavares, 2005). No Brasil, com Carlos Arthur Nuzman a frente do COB desde 1995, o processo não é diferente. ${ }^{27}$ Centralização, personalismo, clientelismo, grandes negócios e muitas suspeitas marcam a história da entidade.

Para se ter uma idéia, em nosso corpus de análise figuram pelo menos 16 registros diretos relacionando o $\mathrm{COB}$ a investigações do Tribunal de Contas da União (TCU) que envolvem mal uso de verba pública, superfaturamento, pagamentos por serviços não prestados, favorecimentos, licitações irregulares etc. Em 2008, por exemplo, após o fracasso da delegação brasileira nos Jogos de Pequim, foi

23 "Morte de Samaranch reabre polêmica no esporte". Folha de S. Paulo, 22 abr. 2010.

24 Samaranch presidiu o COI durante 21 anos, entre 1980 e 2001. Só Pierre de Coubertin, que fundou movimento olímpico, esteve no cargo por mais tempo. Assumiu quando a entidade sofria crises financeiras e boicotes políticos, mas profissionalizou e explorou comercialmente os Jogos, transformando-o num espetáculo envolvendo complexos projetos de marketing.

${ }^{25}$ Com a eleição de Rogge, em 2001, o mandato para presidência do COI foi limitado em 8 anos, sendo permitida a reeleição para um segundo mandato de mais 4 anos.

26 "COI ratifica Rogge para mais um mandato". Folha de S. Paulo, 10 out. 2009.

${ }^{27}$ Nuzman é presidente do COB desde 1995. Foi antes, no período de 1975 a 1995, presidente da Confederação Brasileira de Voleibol (CBV). 
requerida no âmbito do Congresso Nacional a instalação de uma Comissão Parlamentar de Inquérito (CPI) visando a apuração do destino dos recursos públicos repassados às entidades esportivas, bem como dos gastos na organização dos Jogos Pan-Americanos Rio 2007. Entretanto, em 2009, os parlamentares favoráveis à chamada "CPI do Esporte Olímpico" foram constrangidos a interromper as investigações para não atrapalharem a candidatura Rio $2016 .^{28}$

O fato é que o COI e o COB, a despeito do histórico suspeitoso, possuem os direitos de imagem e propriedade intelectual das commodities culturais que envolvem o Movimento e os Jogos Olímpicos, o que lhes confere poder monopolista e vantagem de negociação com os Estados nacionais quando da definição e contratação da sede olímpica. ${ }^{29}$ Senão vejamos o que foi estabelecido pelo Host City Contract.

Se os Jogos Rio 2016 der prejuízo, os cofres públicos devem cobrir o buraco. Se der lucro, $80 \%$ do dinheiro ficará nas mãos do presidente do COB e do Comitê Organizador dos Jogos (COJO). É o que foi estabelecido pelo estatuto do Rio 2016, já aprovado pelas confederações. O documento determina que $20 \%$ do lucro será dado ao COB e outros $20 \%$ serão devolvidos ao COI. Nuzman fará uma proposta para o uso dos outros $60 \%$ para a diretoria do COJO. Pelo estatuto, essa diretoria será composta por Nuzman e cinco vice-presidentes. Um deles será o secretário-geral do COB, cujo Conselho Executivo indica os outros quatro vices. Há membros do governo no Conselho do COJO. São três representantes, um de cada nível. Mas Nuzman tem quatro integrantes aliados nesse organismo. Ou seja, na prática, ele terá o controle sobre a cúpula do comitê organizador. ${ }^{30}$

Como se vê, o COB está no comando do COJO. Como se não bastasse, o Ato Olímpico ${ }^{31}$, com validade até o fim de 2016, assegura garantias e regras especiais para a realização dos Jogos Rio 2016. Atribui ao Estado brasileiro a responsabilidade por qualquer déficit. Prevê que as autoridades federais deverão atuar no controle, na fiscalização e na repressão a ilícitos que infrinjam os direitos sobre os símbolos - bandeiras, lemas, marcas, nome, emblemas, hinos, mascotes e tochas - relacionados aos Jogos. Ademais, suspende, em favor do COJO, os contratos celebrados para utilização de espaços publicitários em aeroportos e áreas federais. Garante, ainda, os serviços de segurança, saúde e comunicação necessários, bem como prevê a edição, pelo poder executivo, de normas complementares futuras que se façam necessárias para a realização dos Jogos.

28 "Eleição de sede pode definir CPI". Folha de S. Paulo, 8 fev. 2009.

${ }^{29}$ Segundo Harvey (2006), a globalização vem promovendo a transformação da cultura, em especial, os eventos culturais, numa espécie de commodities, isto porque possuem cotação e negociabilidade globais. Assim, singularidade e particularidade de determinadas mercadorias ou commodities culturais garante aos seus proprietários aferir renda monopolista, uma vez que tais mercadorias são negociadas junto às coalizões de crescimento no sentido de agregar capital simbólico e marcos de distinção a espaços e lugares.

30 "Nas mãos de Nuzman". Folha de S. Paulo, 29 jul. 2010.

${ }^{31}$ Lei no 12.035/2009. Disponível em: http://www4.planalto.gov.br/legislacao. Acesso em: 25 out. 2010. 
O governo brasileiro reitera o cumprimento dos investimentos necessários para a realização dos Jogos e assegura a oferta de serviços de sua competência antes e durante o evento. O Ato Olímpico prevê ainda o estabelecimento de medidas legais com caráter específico e em período restrito visando a atender às exigências do COI para a época de preparação e realização dos Jogos. ${ }^{32}$

Estamos, deste modo, diante de um conjunto de normas e medidas excepcionais cuja aplicação, mesmo que eventual e emergencialmente, caracterizam o Estado e a cidade de exceção.

Os megaeventos realizam, de maneira plena e intensa, a cidade de exceção. Nesta cidade, tudo passa ao largo dos mecanismos formais-institucionais. Onde foi aprovado o Plano Olímpico do Rio de Janeiro? Não se sabe nem mesmo onde e por quem foi formulado. Nem falar de partidos políticos. A cidade dos megaeventos é a cidade das decisões ad hoc, das isenções, das autorizações especiais... e também das autoridades especiais (Vainer, 2010: 11).

No que se refere ao financiamento, conforme o Dossiê de Candidatura, o orçamento dos Jogos prevê que as três esferas de governo repassem $\mathrm{R} \$ 1,384$ bilhão ao COJO. Esse total significa cerca de um quarto do orçamento do organismo, $\mathrm{R} \$ 5,6$ bilhões. O restante do dinheiro virá de pagamentos do COI, de patrocínios, de venda de ingressos e de licenciamento de produtos, entre outros. Mas esta é a menor fatia do orçamento, pois outros $\mathrm{R} \$ 23,2$ bilhões estão previstos em investimentos públicos em infraestrutura, investimentos a serem coordenados pela Autoridade Pública Olímpica (APO), um consórcio dos governos municipal, estadual e federal cuja criação se deu por exigência do COI a fim de facilitar sua fiscalização sobre o cumprimento dos acordos envolvendo o plano geral de organização. ${ }^{33}$

Como alerta Proni (2008: 51), "as receitas do marketing olímpico pagam os gastos com a organização da festa, mas não com a preparação do local da festa". De tal feita, o custo estimado para realização dos Jogos Rio 2016 é de R $\$ 28,8$ bilhões, o mais alto entre as candidaturas. Em dólares, chega a 14,42 bilhões, enquanto Chicago, Madri e Tóquio projetaram orçamentos de, respectivamente, US\$ 4,82, US\$ 6,13 e US\$ 6,42 bilhões. ${ }^{34}$ Mas, a exemplo dos Jogos Pan-Americanos de 2007, os gastos tendem a subir, ${ }^{35}$ pois esta parece ser uma regra geral na organização dos megaeventos esportivos. O caso Londres 2012 é mais um exemplo. O orçamento inicial havia previa um custo de US $\$ 6,3$ bilhões, com o fundo público se responsabilizando por $85 \%$ do total. Em 2008, a projeção já havia saltado para US $\$ 14,9$ bilhões, com $98 \%$ dos custos assumidos pelo Estado. ${ }^{36}$

\footnotetext{
32 "Câmara aprova PL que institui o Ato Olímpico". Portal de notícias do ME, 16 jun. 2009.

33 "Autoridade Olímpica terá formato de consórcio". Folha de S. Paulo, 19 mar. 2010.

34 "Rio apresenta mais cara candidatura olímpica". Folha de S. Paulo, 14 fev. 2009.

35 O Pan 2007 teve seu custo inicial estimado em R $\$ 410$ milhões, em 2002. Em outubro de 2006, já somavam $\mathrm{R} \$ 2,8$ bilhões. Em março e junho de 2007, os valores cresceram ainda mais: R \$ 3,2 bilhões e R \$ 3,7 bilhões, respectivamente. Ao fim, o crescimento do gasto foi de 793\% em relação à projeção inicial. "Pan registrou caso de irregularidade e fiscalização frouxa". Folha de S. Paulo, 3 out. 2009.

36 Dados do documento "The budget for the London 2012 Olympic and Paralympic Games", do Comitê de Contas Públicas do Reino Unido, citados por Proni (2009)
} 
O sucesso de um projeto olímpico não pode ser avaliado à luz da previsibilidade e exatidão dos números, é o que argumenta Preuss (2008). Para o especialista em economia do esporte que já esteve no Brasil a convite do ME, a imprecisão do orçamento não constitui propriamente um problema, pois a organização de um megaevento esportivo deve ser planejada e orientada a partir do jogo de interesses e das expectativas dos diversos segmentos envolvidos, públicos e privados. Não há, portanto, preocupação retórica alguma de esconder a essência da operação. "No lugar do planejamento moderno, compreensivo, marcado por uma ação diretiva do Estado, um planejamento dito estratégico, que se pretende flexível, amigável ao mercado (market friendly) e orientado pelo e para o mercado (market oriented)" (Vainer, 2009: 4), este é o tom dos discursos dos especialistas que conferem legitimidade ao projeto olímpico brasileiro e que, inclusive, deram substância ao Dossiê de Candidatura.

\section{Mercado}

Retomando o tema do financiamento, do total estimado para a realização dos Jogos, devem ser contabilizados ainda o montante de $\mathrm{R} \$ 138$ milhões referente ao custo da campanha de candidatura. Mais uma vez foi o fundo público a fonte da maior parte dos recursos, R \$ 101 milhões. O restante, veio da iniciativa privada, R\$37 milhões, patrocinados pelo Bradesco, Odebrecht, TAM, Embratel e Grupo EBX. ${ }^{37}$ De acordo com Boito Jr. (2005), o projeto neodesenvolvimentista do Governo Lula - ou liberal-desenvolvimentista, conforme prefere denominá-lo - traduz-se por um modelo de desenvolvimento sem rupturas e pluriclassista, ancorado na parceria com a grande burguesia nacional, o que, obviamente, repercute no projeto olímpico. Nesta direção, é preciso discutir as relações de mercado e parcerias anunciadas para os Jogos Rio 2016, de maneira a detectar os interesses envolvidos.

Caso a caso, iniciemos pelo principal financiador da campanha, que foi o empresário Eike Batista, que investiu R \$23 milhões através da EBX. Considerado o "mecenas" dos Jogos, o empresário mais rico do país parece ter sido também o mais interessado na vitória carioca, sendo o responsável, inclusive, pela controversa "ajuda final" à candidatura.

Ele cedeu o seu jato particular para o governador do Rio, Sérgio Cabral (PMDB), e o prefeito Eduardo Paes (PMDB) viajarem do Brasil para a Dinamarca. "Ele nos ajudou mais uma vez. Liguei e pedi diretamente. Tínhamos um almoço com o presidente da FIFA, Joseph Blatter, na segunda, no Rio, que não podíamos perder também. Se ele não nos cedesse o avião, não teríamos tempo de ensaiar com a delegação brasileira a apresentação final", disse Cabral. ${ }^{38}$

Ocorre que o Grupo EBX possui vários negócios no Rio de Janeiro. Na construção do porto de Açu, por exemplo, o investimento previsto é de cerca de $\mathrm{R} \$ 3$ bilhões, mas o início das obras esbarra

37 “Campanha já consumiu R\$ 138 mi”. Folba de S. Paulo, 2 out. 2009.

38 "Mecenas do Rio, Eike cede jato a políticos". Folha de S. Paulo, 30 set. 2009. 
ainda na concessão de uma série de licenças governamentais. ${ }^{39}$ Outros investimentos do Grupo envolvem as áreas de petróleo, mineração, energia e empreendimentos imobiliários, o que se soma ainda à propriedade da rede Mr Lam, ligada a gastronomia, do navio de cruzeiro Pink Fleet, da Marina da Glória e do Gloria Palace Hotel. ${ }^{40}$ Através dos setores de atuação das empresas de Eike Batista e setores representados pelos demais patrocinadores - financeiro, construção civil, transporte aéreo, telecomunicações -, configura-se um quadro tendencial das parcerias e frações da burguesia a serem privilegiadas na realização dos Jogos.

O Bradesco, que se responsabilizará pelos seguros e serviços financeiros dos Jogos, acompanhado pelo Banco do Brasil, da Caixa, do Santander e do Itaú, já lançou uma série de fundos para aplicação em ações de empresas que tendem a se beneficiar com o evento, projetando ganhos na Bolsa a partir de papéis de companhias de infraestrutura e logística, siderurgia, energia elétrica, saneamento, telecomunicação, transportes, indústria de base e construção civil. ${ }^{41}$ A Odebrecht, que havia liderado o consórcio que realizou as reformas do Maracanã e a construção do estádio do Engenhão no Pan em 2007, além de interessada na infraestrutura esportiva ainda a ser construída, está envolvida também com grande parte das obras do PAC em todo o país. ${ }^{42}$ A TAM foi a responsável pelo transporte aéreo da "cartolagem olímpica" e dirigentes do Comitê Rio 2016. ${ }^{43}$ Por fim, a Embratel, ao patrocinar a campanha, credencia-se como possível fornecedora dos serviços de telecomunicações necessários. ${ }^{44}$

Cabe ainda registrar que do valor total consumido na campanha, $\mathrm{R} \$ 25$ milhões foram gastos na contratação de consultorias internacionais. A principal delas foi a de Mike Lee, também considerado responsável pela vitória da candidatura de Londres 2012. Com experiência no mundo da política, como ex-consultor do Partido Trabalhista - Labour Party - do Reino Unido, e no esporte, como responsável pelo departamento de comunicações da Premier League, o campeonato inglês de futebol, e da Union of European Football Associations (UEFA), especializou-se em propaganda e lobby. ${ }^{45}$ É certo que a campanha publicitária da candidatura contribuiu para a vitória do Rio de Janeiro, isto pois, segundo Sánchez et al

\footnotetext{
${ }^{39}$ O Superporto do Açu está localizado em São João da Barra-RJ, na região norte fluminense. Sua localização é estratégica para a indústria do petróleo, por ser próximo às bacias de Campos e do Espírito Santo, além de poder funcionar como centro logístico de exportação e importação para as regiões Centro-Oeste e Sudeste. Trata-se do maior investimento em infra-estrutura portuária das Américas.

${ }^{40}$ Informações disponíveis em: http://www.ebx.com.br/grupoebx.php. Acesso em: 13 set. 2010.

41 "Fundos visam ganhos com Copa e Olimpíada". Folha de S. Paulo, 5 jul. 2010.

42 "Rio-2016 anuncia apoio de empreiteira". Folha de S. Paulo, 2 jun. 2009.

43 "Campanha se norteia por viagens". Folha de S. Paulo, 28 ago. 2009.

44 "Campanha já consumiu R\$138 mi". Folha de S. Paulo, 2 out. 2009.

45 Graças à pesquisa feita por Mike Lee e sua equipe, o COB possuía dossiês sobre todos os votantes do COI, com seus hobbies e preferências, o que facilitou a campanha corpo a corpo, pois a entidade sabia exatamente o que deveria ser dito e feito para cativar cada um deles. "Inglês surgiu na política e agora ajudará Qatar". Folba de S. Paulo, 6 out. 2009.
} 
(2010), importar know-bow e expertise por parte de consultores identificados com chamados modelos ou experiências de sucesso era visto, no plano simbólico, como um sinal de afirmação e competência.

Os elementos de marketing mobilizados a partir do projeto olímpico funcionaram tanto para fortalecer competitivamente a candidatura como serviram de instrumento político para legitimação e construção de consensos e orgulho cívico em torno do projeto, este último, apresentado como expressão da própria vontade geral da nação. Ocorre que os Jogos Olímpicos, ainda que tenham no espetáculo esportivo e na ideia de união o seu valor aparente, que é justamente o que o marketing e a propaganda buscam evidenciar, tornaram-se, conforme aponta Vainer (2009; 2010), um verdadeiro balcão de negócios da burguesia, ou como prefere denominar Harvey (2006), um "mercado-livre festivo", seja como for, um megaevento que combina projetos hegemônicos e estratégias de acumulação.

\section{Conclusão}

No cenário da concorrência interurbana que marca a disputa entre as cidades sede, inserir o Rio de Janeiro no circuito da economia política dos megaeventos foi algo que cobrou um novo padrão de governo, baseado numa postura empreendedora. Além de mobilizar o poder estatal, as organizações esportivas e interesses privados, deviam se apagar as fronteiras entre ideologias.

O poder de organizar o espaço se origina em um conjunto complexo de forças mobilizado por diversos agentes sociais. (...) Numa região metropolitana, devemos considerar a formação da política de coalizão, a formação da aliança de classes, como base para algum tipo de empreendedorismo urbano. (Harvey, 2006: 171-172).

A coalizão de forças mobilizada, aliás, foi apresentada como uma das maiores qualidades do projeto Rio 2016. Ao contrário do que ocorreu nos Jogos Pan-Americanos de 2007, quando o desalinho entre os três níveis de governo culminou em vaias ao presidente Lula na cerimônia de abertura, ${ }^{46}$ para os Jogos Rio 2016, a articulação do ministro do Esporte, Orlando Silva, com as autoridades cariocas, o governador Sérgio Cabral e o prefeito Eduardo Paes, apresentou-se como um dos pilares de sustentação política da candidatura, uma qualidade frequentemente enfatizada por Nuzman. ${ }^{47}$

46 Na cerimônia de abertura dos Jogos Pan-Americanos de 2007, o presidente Lula estava acompanhado de vários ministros, dentre as quais, Dilma Rousseff. Também estavam presentes, além do governador e prefeito do Rio de Janeiro, Sérgio Cabral, do PMDB, e Cesar Maia, do DEM, o governador e prefeito de São Paulo, José Serra, do PSDB, e Gilberto Kassab, do DEM. Frente à disputa entre a aliança governista, PT-PMDB, e oposição, PSDB-DEM, o PT insinuou, a partir da divulgação de um vídeo que mostra um coro de vaia sendo ensaiado às vésperas do Pan, que a ação foi orquestrada por grupo ligado ao então prefeito Cesar Maia. "Lula se diz triste e insinua armação em vaias". Folha de S. Paulo, 17 jul. 2007.

47 Nuzman, ao comentar as possibilidades de êxito da candidatura Rio 2016, ressaltou que esta reunia todas as condições de vitória, pois contava com o integral apoio dos governos federal, estadual e municipal, uma coalizão 
O projeto Rio 2016 foi considerado o melhor pelo relatório da Comissão de Avaliação do COI. O documento destaca que a transição do comitê de candidatura para um comitê organizador Rio 2016 se beneficiaria da continuidade da experiência e do conhecimento acumulados nos Jogos Pan-Americanos Rio 2007. E ressalta ainda o integral apoio dos governos federal, estadual e municipal.

Como vimos, esta coalizão transcende ao poder estatal, aglutinando interesses das entidades de administração do esporte e empresariais. Delineia-se, assim, o que estamos definindo como bloco olímpico, ou seja, o bloco de poder inerente à organização dos Jogos Rio 2016. Na teoria do Estado, mais especificamente na obra de Poulantzas (2000), a noção de bloco de poder permite identificar o favorecimento dos interesses econômicos de uma ou mais frações da classe dominante em detrimento de outras frações, considerando tanto sua ação política como a posição particular que ocupa no processo de produção num momento e situação determinados. Assim, o Estado se constitui como agente organizador da hegemonia de dadas frações de classe no seio do bloco de poder.

No modelo desenvolvimentista do governo Lula, coube ao Estado apoiar as grandes empresas nacionais no sentido de lhes conferir competitividade no mercado mundial. Neste sentido, de acordo com a análise de Boito Jr (2005), não houve ruptura, ao contrário, a aliança com a grande burguesia e o fortalecimento do capital nacional privado constitui um dos traços definidores do bloco de poder e modelo de desenvolvimento conduzido e organizado pelo governo de Lula. No que toca ao esporte, os parceiros de interação do Estado, bem como a estrutura e ordem definidoras das políticas públicas para o setor, sempre foram dadas por um sistema verticalizado de cima para baixo, a partir das entidades de administração (Bracht, 1997; Manhães, 2002). A chegada do PT ao Estado também não trouxe ruptura com o status quo da área, ${ }^{48}$ pois o pragmatismo impediu qualquer possibilidade de debate programático em torno do setor.

Conclui-se, portanto, que a formação da agenda e sucesso da candidatura Rio 2016 resultam de uma coalizão de forças cujas pretensões e interesses repercutem como a própria vontade geral, isto é, o interesse geral de toda a sociedade ou nação. No entanto, além de ter reforçado a condição de Lula como condottiere e mito, tal projeto se articulou ao projeto de governo, ao modelo neodesenvolvimentista e à política externa de reposicionamento do país na geopolítica mundial. Ancorou-se, por um lado, numa política conservadora de aproximação e subordinação do Estado brasileiro às entidades proprietárias dos Jogos, COI e COB, e, por outro, num projeto empreendedor

ausente nas postulações de 2004 e 2012. "Porque a hora e a vez do Brasil enfim chegaram." Carlos Arthur Nuzman. Folha de S. Paulo, 27 set. 2009.

48 Segundo Castellani Filho (2009), em busca de legitimidade no setor esportivo, o ME, cuja direção foi "terceirizada" pelo PT ao PC do B, desenvolveu uma postura de submissão voluntária às entidades de administração, $\mathrm{COB}$ e $\mathrm{CBF}$, resultando no alinhamento das políticas para o setor aos interesses da fração conservadora do campo esportivo. 
orientado para o mercado, correspondendo aos interesses de determinadas frações da burguesia, o que corresponde ao intento de reorganização do capitalismo brasileiro.

\section{Referências}

ALMEIDA, P. R. (2004). Uma política externa engajada: a diplomacia do governo Lula. Revista Brasileira de Política Internacional, Brasília, v. 47, n. 1, p. 162-184.

BARDIN, L. (2010). Análise de conteúdo. 4 ed. Lisboa: Edições 70.

BOITO JUNIOR, A. (2005). A burguesia no governo Lula. Crítica Marxista, Rio de Janeiro, v. 21, p. 52-77.

BOUDENS, E. (2007). A revolução da oportunidade: o esporte no primeiro mandato de Lula, segundo Lula. Rio de Janeiro: Publit.

BRACHT, V. (1997). Sociologia crítica do esporte: uma introdução. Vitória: UFES, CEFD.

BRASIL (2010). III Conferência Nacional do Esporte: texto básico. Brasília: Governo Federal, Ministério do Esporte.

CASTELLANI FILHO, L. (2009). O PT, a política esportiva brasileira e a síndrome de Estocolmo. Disponível em: http://www.observatoriodoesporte.org.br. Acesso em: 5 nov. 2010.

COMITÊ RIO 2016 (2009). Rio 2016: cidade candidata. Dossiê de candidatura. Rio de Janeiro: COB.

FRANCO, M. L. P. B. (2005). Análise de conteúdo. 2 ed. Brasília: Liber Livro.

GIAMBIAGI, F. et al. (2010). O papel do Estado, o projeto olímpico e a importância do legado. Estudos e Pesquisas, Rio de Janeiro, 361, p. 1-86.

HARVEY, D. (2006). A produção capitalista do espaço. 2 ed. São Paulo: Annablume.

MANHÃES, E. D. (2002). Políticas de esportes no Brasil. 2. ed. Rio de Janeiro: Paz e Terra.

MELO, M. A. (2007). As sete vidas da agenda pública brasileira. In: RICO, E. M. (Org.). Avaliação de políticas sociais: uma questão em debate. 5 ed. São Paulo: Cortez; Instituto de Estudos Especiais PUC-SP.

MERCADANTE, A. (2010) O governo Lula e a construção de um Brasil mais justo. São Paulo: Fundação Perseu Abramo.

PARANÁ, D. (2008). Lula, o filho do Brasil. 3 ed. São Paulo: Fundação Perseu Abramo.

POCHMANN, M. (2009). O emprego no desenvolvimento da nação. São Paulo: Boitempo.

POULANTZAS, N. (2000) O Estado, o poder, o socialismo. 4 ed. São Paulo: Paz e Terra. 
PREUSS, H. (2008). Impactos econômicos e megaeventos: copa do mundo de futebol e jogos olímpicos. In: RODRIGUES, R. P. et al. (Orgs.). Legados de megaeventos esportivos. Brasília: Ministério do Esporte.

PRONI, M. W. (2004). A metamorfose dos jogos olímpicos (1896-1996). Anais do $17^{\circ}$ Encontro Regional de História. Campinas.

PRONI, M. W. (2009). Observações sobre os impactos econômicos esperados dos jogos olímpicos de 2016. Motrivivência, Florianópolis, n. 32/33, p. 49-70.

RESENDE, C. A. R. (2010). O Esporte na política externa do governo Lula: o importante é competir? Meridiano 47, Brasília, v. 11, n. 122, p. 35-41.

SÁNCHEZ, F. et al. (2010). A cidade olímpica como construção política e simbólica: notas sobre o projeto Rio 2016. Anais da International Conference Mega-Events and the City. Niterói.

SARDINHA, T. B. (2008). Lula e a metáfora da conquista. Linguagem em (dis)curso, Tubarão, v. 8, n. 1, p. 93-120.

SIMSON, V.; JENNINGS, A. (1992). Os senhores dos anéis: poder, dinheiro e drogas nas olimpíadas modernas. São Paulo: Best Seller.

SINGER, A. (2009). Raízes sociais e ideológicas do lulismo. Novos Estudos, São Paulo, 85, p. 83-102.

SINGER, A. (2010). A segunda alma do Partido dos Trabalhadores. Novos Estudos, São Paulo, 88, p. 89-111.

SOUZA, L. R. (2003). Neodesenvolvimentismo e o governo. Princípios, São Paulo, n. 69, p. 18-28.

TAVARES, O. (2005). Comitê Olímpico Internacional. In: GONZÁLEZ, F. J.; FENSTERSEIFER, P. E. (Orgs.). Dicionário crítico de educação física. Ijuí: Unijuí.

VAINER, C. (2009). Rio 2016: um jogo (olímpico?) de cartas marcadas. Jornal dos Economistas, Rio de Janeiro, n. 245, p. 3-4.

VAINER, C. (2010). Megaeventos e cidade de exceção. Anais da International Conference MegaEvents and the City. Niterói. 